\title{
Non-target effects of ten essential oils on the egg-parasitoid Trichogramma evanescens
}

\author{
Louise van Oudenhove ${ }^{1, *}$, Aurélie Cazier ${ }^{1}$, Marine Fillaud $^{1}$, Anne-Violette Lavoir ${ }^{1}$, \\ Hicham Fatnassi ${ }^{1,2}$, Guy Pérez ${ }^{1}$ \& Vincent Calcagno ${ }^{1}$ \\ (1) Institut Sophia Agrobiotech, INRAE, Université Côte d'Azur, CNRS, France. \\ (2) International Center for Biosaline Agriculture, Dubai, United Arab Emirates.
}

Author for correspondence $(*) \quad$ louise.vanoudenhove @ inrae.fr

6 Abstract Essential oils (EOs) are increasingly used as biopesticides due to their insecticidal potential. This study addresses their non-target effects on a biological control agent: the egg parasitoid Trichogramma evanescens. In particular, we tested whether EOs affected parasitoid fitness either directly, by decreasing pre-imaginal survival, or indirectly, by disrupting parasitoids' orientation abilities. The effect of Anise, Fennel, Sweet orange, Basil, Coriander, Oregano, Peppermint, Mugwort, Rosemary and Thyme EOs were studied on five strains of $T$. evanescens. Specific experimental setups were developed, and data obtained from image analysis were interpreted with phenomenological models fitted with Bayesian inference. Results highlight the fumigant toxicity of EOs on parasitoid development. Anise, Fennel, Basil, Coriander, Oregano, Peppermint and Thyme EOs are particularly toxic and drastically reduce the emergence rate of $T$. evanescens. Most EOs also affect parasitoid behavior: (i) Basil, Coriander, Oregano, Peppermint, Mugwort and Thyme EOs are highly repellent for naive female parasitoids; (ii) Anise and Fennel EOs can have repellent to attractive effects depending on strains; and (iii) Sweet orange, Oregano and Rosemary EOs have no detectable impact on orientation behavior. This study shows that EOs fumigation have non-target effects on egg parasitoids. This highlights the need to cautiously precise the deployment framework of biopesticides in an agroecological perspective.

Keywords biocontrol; egg parasitoids; non-target effects; essential oils; toxicity; behavior; olfaction; Bayesian inference 


\section{Introduction}

Botanical pesticides (BPs) are often presented as an ecofriendly solution for pest management (Regnault-Roger, 1997; Regnault-Roger et al., 2012; Mossa, 2016; Pavela and Benelli, 2016; Isman, 2020). Produced from plant metabolites, BPs exploit plant allelochemicals for their repellent or toxic effects on many arthropods (RegnaultRoger, 1997; Mossa, 2016). Among the BPs, Essential Oils (EOs), the fraction of volatile fragrant compounds derived from aromatic plants, affect a wide range of insect taxa (Regnault-Roger, 1997; Regnault-Roger et al., 2012) through different neurotoxic effects (Mossa, 2016; Pavela and Benelli, 2016). They can be repellent (e.g. Foeniculum vulgare (Bedini et al., 2016), see also Nerio et al. (2010) for a review), antifeedant (e.g. Ocimum basilicum (Saroukolai et al., 2014)) or antiovipositant (e.g. Coriandrum sativum (Saxena and Basit, 1982)), inhibit digestion, decrease reproduction by ovicidal (e.g. Origanum vulgare (Baricevic et al., 2001)) or larvicidal effects (e.g. Citrus aurantium (Sanei-Dehkordi et al., 2016); Mentha piperita (Morey and Khandagle, 2012); Thymus vulgaris (Szczepanik et al., 2012)), or directly decrease adult survival (e.g. Pimpinella anisum (Sampson et al., 2005); Artemisia vulgaris (Wang et al., 2006); Rosmarinus officinalis (Hanane et al., 2018))

BPs, and more specifically EO-based products, are usually considered as low-risk products because they present a low toxicity on non-target vertebrates and show little persistence in the environment (Regnault-Roger et al., 2012; Pavela and Benelli, 2016). However, the effects on untargeted arthropods, including sub-lethal impacts on beneficial insects, need to be better documented (Regnault-Roger et al., 2012; Haddi et al., 2020; Siviter and Muth, 2020). EOs might actually induce non-target effects against pollinating insects such as bees (Vital et al., 2018), and natural enemies such as parasitoids (Ilboudo, 2009; González et al., 2013; Poorjavad et al., 2014). In an Integrated Pest Management (IPM) context, the BP applications might complement natural regulations by parasitoids and predators. The efficiency of such programs might thus rely on the innocuousness of these biopesticides for natural enemies.

Trichogramma (Hymenoptera: Trichogrammatidae) are tiny egg parasitoids used as biocontrol agents to control many Lepidopteran pests around the world (Consoli et al., 2010; Van Lenteren, 2012). In particular, T. evanescens Westwood is commercialized in augmentative biocontrol programs in many crops such as corn, vegetable or sugar-cane (Hassan, 1993). Moreover, T. evanescens naturally occurs in many agricultural fields and natural environments in Eurasia (Pintureau, 2009). Non-target effects on T. evanescens could thus have both economical and ecological consequences. Regarding EOs, some Trichogramma species are sensitive to both fumigant and contact toxicity: EOs might reduce the longevity and the fecundity of parasitoids, affect their reproductive behavior and have an impact on their progeny (Poorjavad et al., 2014; Parreira et al., 2018a,b).

EOs used in IPM programs might affect parasitoids not only directly, because of their toxicity on development, survival and reproduction, but also indirectly, as fragrant products, by disrupting parasitoids' host searching ability. Indeed, the fitness of egg parasitoids is highly dependent on their ability to locate and recognize their host (Price, 1975). To this purpose, Trichogramma depends on many chemical cues both from their hosts and the plants (Consoli et al., 2010; Wajnberg and Colazza, 2013). Foraging females can rely on chemical cues coming directly from the host stage they parasitize, such as compounds present on the surface of the eggs (Frenoy et al., 1992; Renou et al., 1992), or signals from different host stages such as larval frass (Rani et al., 2007), wing scales (Lewis et al., 1975; Ananthakrishnan et al., 1991; Fatouros et al., 2005; Milonas et al., 2009) or sex pheromone (Noldus et al., 1990; Frenoy et al., 1992; Boo and Yang, 1998; Geetha, 2010). Trichogramma also exploit chemical signals from the plant emitted either constituvely (Constitutive Volatile Organic Compounds, (Altieri et al., 1982; Romeis et al., 1997; Boo and Yang, 1998; BAI et al., 2011; Wilson and Woods, 2016)) or induced by the presence of hosts such as hosts' feeding (Herbivore-Induced Plant Volatiles (Peñaflor et al., 2011)) or ovipositing (Oviposition-induced plant volatiles (Fatouros et al., 2005, 2012)) behavior. 
The objective of this study is to evaluate the non-target effects of 10 essential oils showing insecticidal potential (Anise, Fennel, Sweet orange, Basil, Coriander, Oregano, Peppermint, Mugwort, Rosemary, Thyme) on five strains of the biocontrol agent $T$. evanescens. Direct non-target effects were evaluated on parasitoid development by estimating the fumigant toxicity of EOs on pre-imaginal survival. Indirect non-target effects on paratoid behavior were considered by determining the consequences of EO fumigation on parasitoid movement using a 4-way olfactometer.

\section{Materials \& Methods}

\section{Insects}

Five strains of $T$. evanescens were obtained from the Biological Resource Centre Egg Parasitoids Collection "Ep-Coll" (Ris et al., 2018). Strain AF017 had been collected in 2015 on Olea europaea in Bergheim (France). Strain AM002 had been collected in 2015 on Cydonia oblonga in Estrablin (France). Strain BL065 had been collected in 2016 on Malus sp. in Le Change (France). Strain ESP467 had been collected in 2016 on Phaseolus vulgaris in Olazti (Spain). Strain MURU222 had been collected in 2016 on Solanum lycopersicum in Orthez (France). AF017 and AM002 had been reared on isofemale lines for seven generations.

Parasitoids have been reared in the laboratory on UV-sterilized Ephestia kuehniella Zeller (Lepidoptera: Pyralidae) eggs. At each generation, about $500 \pm 50$ eggs of E. kuehniella fixed to a card with diluted glue, were presented to emerging parasitoids for them to parasite. Temperature alterned between $19 \pm 1{ }^{\circ} \mathrm{C}$ and $25 \pm 1{ }^{\circ} \mathrm{C}$ according to the experimental schedule, in order to modulate the generation time as needed. Light conditions were L12:D12 photoperiod and humidity was $70 \pm 10 \% \mathrm{RH}$.

\section{Essential oils}

We studied the effects of 10 Essential Oils: Green anise (Pimpinella anisum, Apiaceae); Fennel (Foeniculum vulgare, Apiaceae); Sweet orange (Citrus x aurantium var. dulcis, Rutaceae); Basil (Ocimum basilicum, Lamiaceae); Coriander (Coriandrum sativum, Apiaceae); Oregano (Origanum vulgare, Lamiaceae); Peppermint (Mentha x piperita, Lamiaceae); Mugwort (Artemisia vulgaris, Asteraceae); Rosemary (Rosmarinus officinalis, Lamiciaceae); Thyme (Thymus vulgaris, Lamiaceae); All EOs were obtained from Esperis s.p.a..

The full chemical composition of the different EOs is available in the Supplementary Information S.1. Hierarchical clustering show no particular trend linked to the plant family (Fig S.1). However, Anise and Fennel EOs set apart, probably because they both are mainly composed of anethole, known to exhibit insecticidal activity (Dunan et al., 2021; Sousa et al., 2021). Furthermore, Rosemary and Thyme EOs also distinguish themselves since they are heterogeneous (several major constituents) contrary to the other homogeneous EOs, that are mainly composed of a single majority component ( $>50 \%$, Table S.1).

\section{Experimental design}

\section{Pre-imaginal survival}

For each Trichogramma strain, the day before the experiment (D-1), small patches with about $25 \pm 7 E$. kuehniella eggs were parasitized during $24 \mathrm{~h}$ by emerging parasitoids (about 100 individuals, sex-ratio around 
$0.45 \pm 0.11$ ). On D-day, each patch was placed individually in a $1 \mathrm{~cm}$ diameter and $15 \mathrm{~cm}$ long glass tube (Fig 1). On one extremity, glass tubes were closed with a $4 \mathrm{~cm}$ wet cotton plug in order to increase relative humidity inside the tube (about $40 \% \mathrm{RH}$ ). On the other extremity, a $4 \mathrm{~cm}$ dry cotton plug with the treatment that was either nothing (control tubes) or, for each EO treatment, $5 \mu L, 10 \mu \mathrm{L}$ or $20 \mu \mathrm{L}$ of pure Essential Oil. Both cotton plugs remained in place during all the experiment. Full air volume inside the glass tubes was about $5.5 \mathrm{~cm}^{3}$. Each treatment was replicated 10 times, meaning 310 tubes for a single strain. Tubes were placed horizontally, at randomly shuffled positions, on plastic racks, each rack supporting 10 tubes (Fig 1). The 31 racks were placed under a hood with minimal aspiration. There was no light and temperature was about $20.1 \pm 0.3{ }^{\circ} \mathrm{C}$.

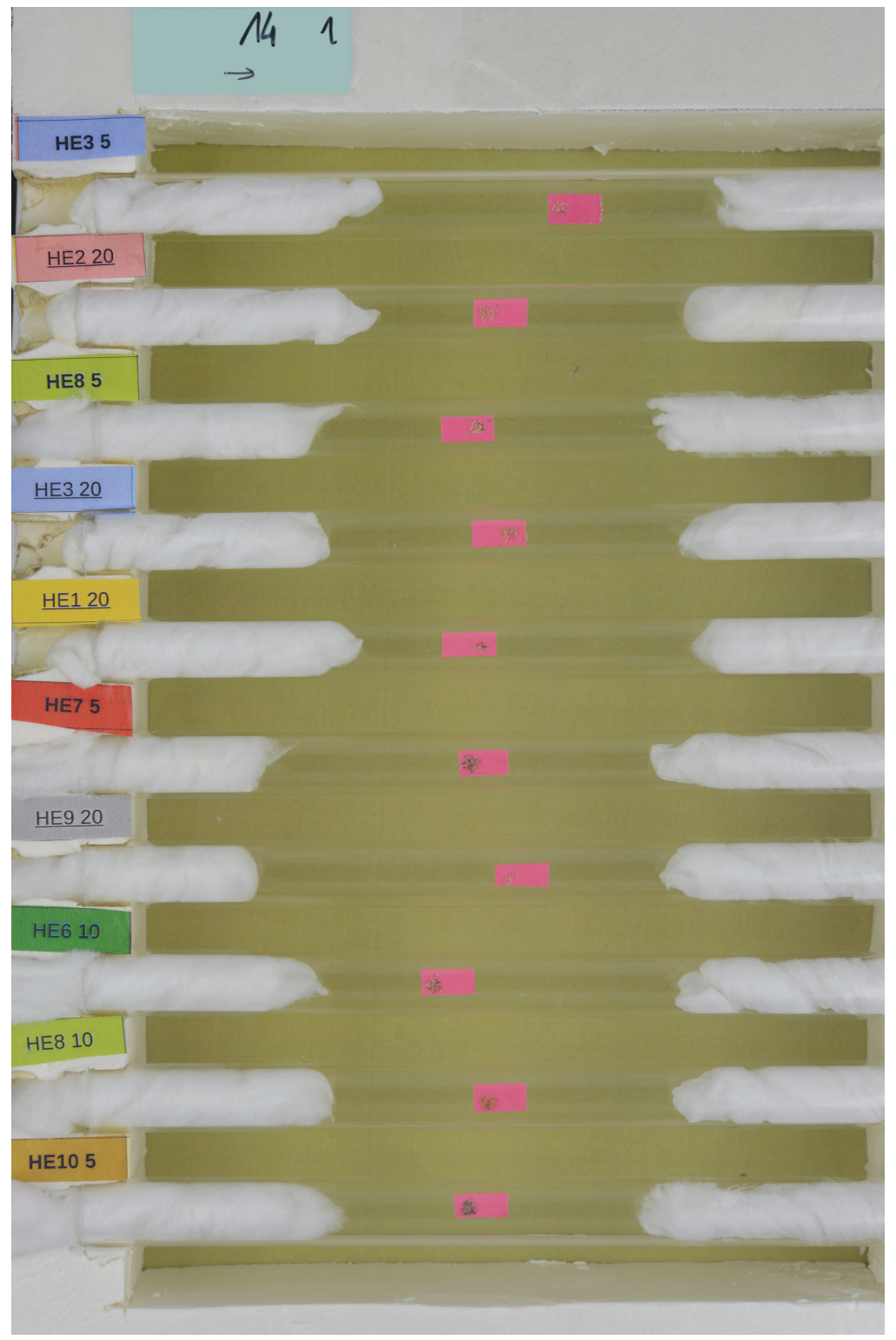

Figure 1: The plastic rack with 10 random glass tubes. Pink cards with egg patches stand inside the glass tubes closed with wet cotton plug on the right side, and Essential Oil treatment (or no additive for control) on the left side. Colored labels identify the Essential Oil and specify the quantity applied (in $\mu L$ ).

Five days after having been parasitized, when Trichogramma larvae pupate, host eggs turned black (Volkoff et al., 1995). In order to evaluate parasitoid pupation, pictures of the racks were made with a Nickon D800 DSLR on day $(D+5)$. Adults emerged on day $(D+14)$, lived and died. On day $(D+19)$, in each tube, dead parasitoids were counted to evaluate adult emergence. 

the exposure chamber.

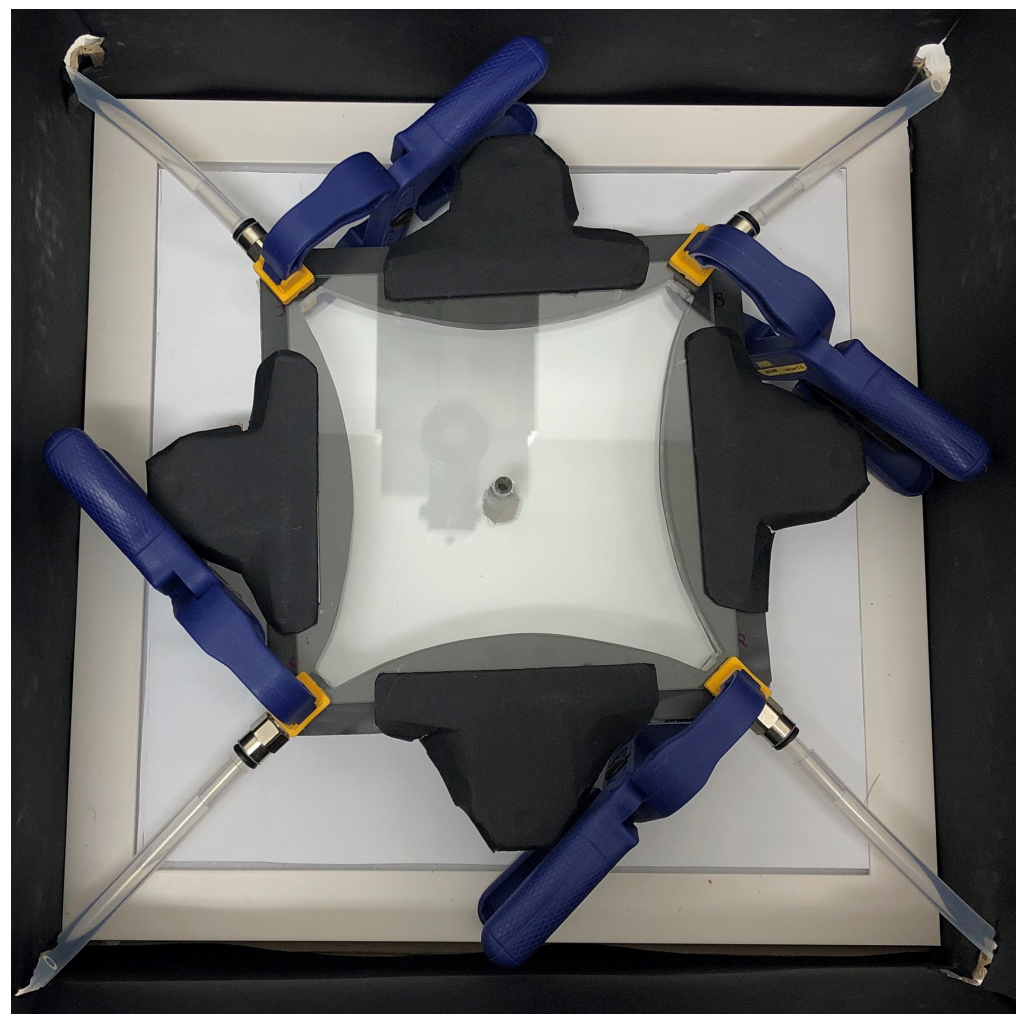

Figure 2: The exposure chamber of the four-arm olfactometer hold closed with pliers was placed on a light pad inside a black box. Air flows from the tubes at the four extremity and evacuate in the central hole.

\section{Olfactometry bioassays}

Behavioral responses were observed in a four-arm olfactometer (Pettersson, 1970; Vet et al., 1983) inspired, but scaled-up, from the one used by Kaiser (1988). The exposure chamber is a four-pointed star-shape $0.8 \mathrm{~cm}$ thick, sealed on both sides by two $14 \times 14 \mathrm{~cm}^{2}$ glass sheets, with fluorocarbon rubber sheet to ensure air tightness. The bottom glass sheet has a hole ( $5 \mathrm{~mm}$ in diameter) in the center, through which the air flowed out. Full air volume inside the exposure chamber is about $113.1 \mathrm{~cm}^{3}$. The exposure chamber was hold firmly closed with eight pliers (Fig 2). Air circulation inside the exposure chamber has been modelized with Computational Fluid Dynamics to check that the airflow was laminar (see Supplementary Information S.2 for details). This result was confirmed experimentally with smoke tests that show a smooth and regular repartition of the smoke inside

inside a black box. Air flows from the tubes at the four extremity and evacuate in the central hole.

Air is pushed in the dispositive with an air pump (AquaOxy 2000), filter with Whatman Hepa-vent filter device, and splitted in four arms. Each of the four air flows is set to $1.6 L . h^{-1}$ with a flowmeter (DK 800 / PV) and sent into $400 \mathrm{~mL}$ distilled water in a $500 \mathrm{~mL}$ Pyrex glass flask. Air from this first flask is sent either into an empty $500 \mathrm{~mL}$ Pyrex glass flask or to a $500 \mathrm{~mL}$ Pyrex glass flask with a VWR filter paper with/without a drop of essential oil. Changing connected flask is made possible with a metal air valve. Both flasks are connected to another metal air valve that commands the connection with the exposure chamber. In the exposure chamber, air flows from the four extreme points and create four odour fields that evacuate in the hole in the centre of chamber's floor. Air from the hole is gently sucked and extracted out of the room. All connections are fluoropolymere tubes and stainless steel connectors.

Before the beginning of an experiment, the exposure chamber was placed on a led panel $(3546 \mathrm{~lm})$ and surrounded by $15 \mathrm{~cm}$ high opaque border to avoid any interference from the environment. A DSLR camera (Nikon D810) was fixed $50 \mathrm{~cm}$ above the exposure chamber for image acquisition. About 60 female parasitoids 
were brought into contact with the central hole under the exposure chamber. We waited for at least 10 minutes for parasitoids to climb up and enter the exposure chamber. Meanwhile, the Pyrex flasks with VWR filter paper were prepared: two without EO at two opposite corners, and two with EO (one with $5 \mu L$ and one with $10 \mu L$ ) at the two other corners. For each tested combination strain/EO, four replicates were performed, each time with a different arrangement of the flask positions. After each experiment, all the material was carefully cleaned with $90 \%$ ethanol, washed with distilled water and dried. The flasks with VWR filter paper were isolated from air circulation with the metal air valves. When the experiment started, parasitoid movements in the exposure chamber were first recorded during 5 min (hereafter named control video). Then, the flasks with VWR filter paper (with or without EOs) were connected to the air circulation and parasitoid movements were recorded for another 15 minutes (hereafter named treatment video). The camera settings were ISO 160, F8, with a resolution of 6.7 MP and a framerate of 25 fps.

\section{Image analysis}

\section{Pre-imaginal survival}

Pictures of host eggs made on day (D+5) were processed with the ImageJ software (Schneider et al., 2012; Schindelin et al., 2012), specifically with the plugin CODICOUNT (Perez et al., 2017). A dedicated macro was written to automatically identify and process each tube in the picture of an entire rack of tubes (code available upon request). The CODICOUNT plugin counted, for each tube, the number of dark and bright pixels in the patch of host eggs, using a segmentation threshold adjusted using manual annotations on a subset of pictures. The two categories of pixels corresponded respectively to black (parasitized) or white (unparasitized) host eggs.

Earlier tests and uses of the method suggested a close linear relationship between the number of pixels and the number of eggs (Burte et al., 2022). The first step was thus to make explicit the link between the number of pixels and the number of eggs. To this end, for each strain, 30 random pictures have been manually counted in order to get both the number of eggs and the number of pixels. Then, for each kind of eggs (black or white), a model was built where the number of black and white eggs (EggsB and EggsW) was a realisation of a Poisson function whose parameter was a linear function of the number of pixels ( $\mathrm{xBB}$ and $\mathrm{P} \times \mathrm{W})$, such as, for all replicate $k \in[1,150], \mathrm{EggsB}_{k} \sim \mathcal{P}\left(\gamma_{B\left(j_{k}\right)}+\theta_{B\left(j_{k}\right)} \mathrm{PxB}_{k}\right)$ and $\mathrm{EggsW}_{k} \sim \mathcal{P}\left(\gamma_{W\left(j_{k}\right)}+\theta_{W\left(j_{k}\right)} \mathrm{PxW}_{k}\right)$. To take into account possible specificity for the strain $j$, parameters $\gamma$ and $\theta$ were allowed to vary between strains, such as $\gamma_{B(j)} \sim \mathcal{N}\left(\gamma_{B_{0}}, \sigma_{\gamma, B_{0}}\right), \gamma_{W(j)} \sim \mathcal{N}\left(\gamma_{W_{0}}, \sigma_{\gamma, W_{0}}\right), \theta_{B(j)} \sim \mathcal{N}\left(\theta_{B_{0}}, \sigma_{\theta, B_{0}}\right)$ and $\theta_{W(j)} \sim \mathcal{N}\left(\theta_{W_{0}}, \sigma_{\theta, W_{0}}\right)$ for each strain $j$. All Parameters were estimated with Bayesian inference from non-informative priors (see Supplementary Information S.3.1 for details).

From these estimations, both the number of black and white eggs (EggsB and EggsW) were predicted from the number of pixels for all patches (see Supplementary Information S.3.1 and Burte et al. (2022) for prediction accuracy). The data available after this first step analysis were thus, for all the 310 patches: NbEggs, the total number of eggs (NbEggs $=E g g s B+E g g s W) ; \mathrm{NbB}$ the number of parasitoid pupae $\mathrm{NbB}=\mathrm{EggsB})$; Pr5 the effective parasitism rate after five days $\left(\operatorname{Pr} 5=\frac{\text { Eggs } B}{\text { EggsB EggsW }}\right)$.

\section{Olfactometry bioassays} for the control videos (three pictures in total) and one picture each three minutes for the treatment videos (six pictures in total). Each picture was manually counted with the assistance of a custom ImageJ macro (Schneider 
et al., 2012; Schindelin et al., 2012). The location of all parasitoids was marked, as well as the exact location of the chamber (central hole and four extreme points, Fig 3). The ImageJ macro then automatically attributed $(\mathrm{x}, \mathrm{y})$ coordinates to each parasitoid, and assigned it to one of 16 portions of the olfactometer chamber, defined with respect to the presence/absence of odors and the shape of the air (see Fig 3 ; code available upon request). Zones between adjacent fields (i.e. zones with mixed air-flow) were omitted from analyses. The resulting data table contained the number of parasitoids in the whole exposure chamber NbTotal $(t)$ and in each of the four air fields $\mathrm{Nb}_{z}(t), z \in\{1,2,3,4\}$, for the different times $t(t \in\{0,2,4\}$ for control experiments and $t \in\{0,3,6,9,12,15\}$ for treatment experiments).

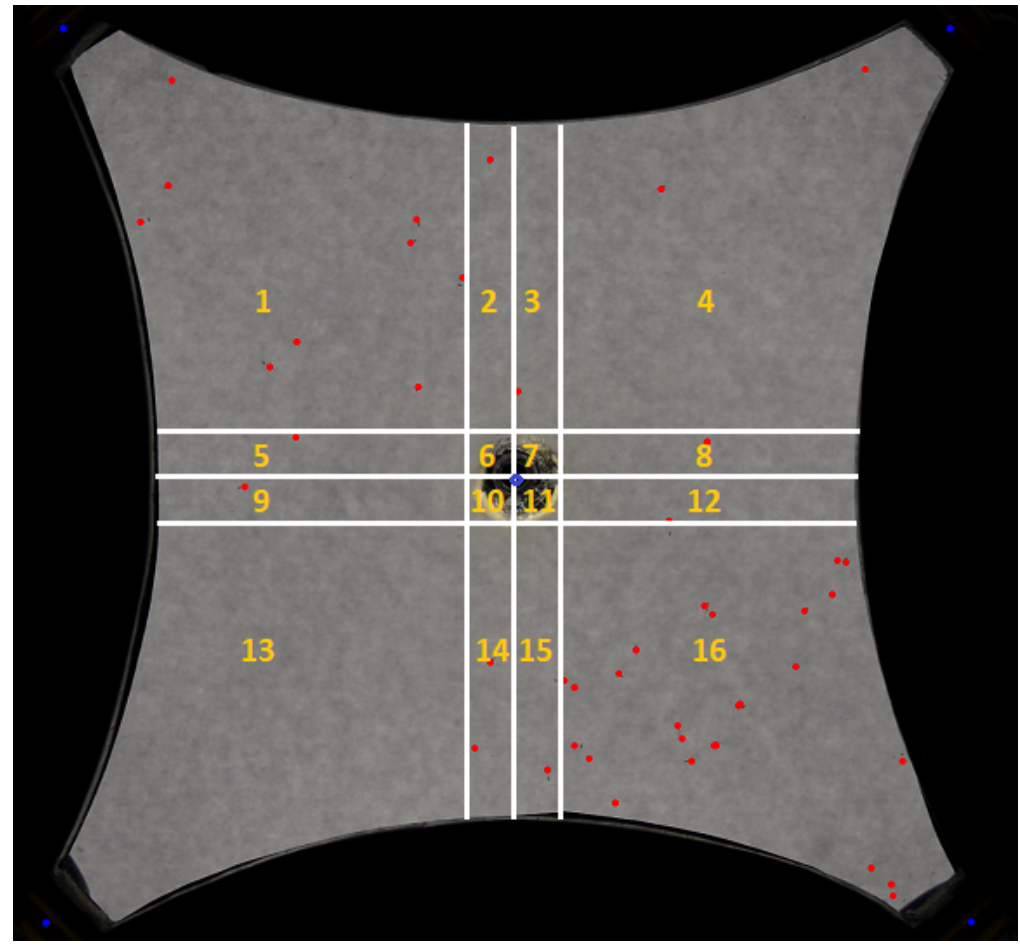

Figure 3: Exposure chamber of the four-arm olfactometer treated by ImageJ. Blue points indicate orientation by identifying the central hole and the extreme points. Red points are manually marked trichograms. 16 zones are automatically defined. To make sure odor fields are homogeneous, adjacent fields (50pt horizontal and vertical central strips from the central lines) are not taken into account: only zones 1, 4, 13 and 16 are kept for the analyses (and named zones 1, 2, 3, 4 hereafter). All others zone are gather together and named $y$. This picture is extracted from a treatment video.

\section{Statistical analysis}

Statistical analysis were conducted with the R software (version 3.6.3), using R2jags for Bayesian analyses and ggplot2 for most visualizations (R Core Team, 2020; Su and Yajima, 2015; Wickham, 2016).

\section{Pre-imaginal survival}

A conceptual model that describes how essential oil affect parasitoid development was built (see Supplementary Information S.3.2 for details). This model includes three steps: (i) how a given patch is paratized? (ii) do parasitoids develop into pupae inside the host eggs? and (iii) do parasitoid pupae develop into a living adults that emerge from the host egg? 
Phase (i) - parasitism: each patch $l$ is parasitized with a rate $\rho_{l}$ that depends on the strain $j$ with a given variability such as $\rho_{l} \sim \mathcal{N}\left(\kappa_{j}, \sigma_{R}\right)$. This normal distribution was truncated below $\mathrm{Pr} 5_{l}$ and above 1 in order to avoid non-meaningful values. For each patch, the number of parasitized eggs is thus $\mathrm{NbP}_{l} \sim \mathcal{B}$ in $\left(\mathrm{NbEggs}_{l}, \rho_{l}\right)$.

Phase (ii) - parasitoid pupation: parasitoid egg survival is assumed to rely on a survival rate that depends on the EO concentration $\mathrm{C}_{l}$ such as, for five days of exposition to EO, parasitoid early survival probability is $\left(\delta e^{-\alpha_{i, j} \mathrm{C}_{i}}\right)^{5} . \delta$ is natural survival rate. Parameter $\alpha_{i, j}$ represents daily sensibility to EO $i$ for the eggs of strain $j$. The number of eggs turning black is thus $\mathrm{NbB}_{l} \sim \mathcal{B} i n\left(\mathrm{NbP}_{l},\left(\delta e^{-\alpha_{i, j} \mathrm{C}_{i}}\right)^{5}\right)$.

Phase (iii) - parasitoid emergence: adult emergence, like phase (ii), depends on parasitoid pupal survival probability $\left(\delta e^{-\left(\alpha_{i, j}+\beta_{i, j}\right) C_{l}}\right)^{9}$. Since adults emerged at (D+14), parasitoid pupae are exposed $14-5=9$ days to EOs. The number of emerging adults is thus $\mathrm{NbA}_{l} \sim \mathcal{B}$ in $\left(\mathrm{NbB}_{l},\left(\delta e^{-\left(\alpha_{i, j}+\beta_{i, j}\right) \mathrm{C}_{l}}\right)^{9}\right) . \alpha_{i, j}+\beta_{i, j}$ is daily sensibility to EO $i$ for the pupae of strain $j$. Parameter $\beta_{i, j}$ represents the differences between first instars (eggs and larvae) and pupae sensibility: if pupae are more sensitive than larvae, $\beta_{i, j}>0$, if they are more resistant, $\beta_{i, j}<0$, and if both pupae and larvae are equally sensitive, $\beta_{i, j}=0 . \beta_{i, j}$ is not necessarily linked to the physiology of the pupae but could also be understood as a cumulative effect.

To estimate the parameters of this model, we performed Bayesian inference (details are provided in the Supplementary Information S.3.2). We tested different possibilities for both parameters $\alpha_{i, j}$ and $\beta_{i, j}$ to study the influence of the EO and the specifity of the strain (Table 1). Parameter $\alpha$ was either a sum of EO and strain effects with interaction between both effects $\left(\alpha_{i, j}\right)$ or without interaction $\left(\alpha 1_{i}+\alpha 2_{j}\right)$, or only dependent on EO $\left(\alpha 1_{i}\right)$. Parameter $\beta$ was either null, or EO dependent $\left(\beta 1_{i}\right)$, or strain dependent $\left(\beta 2_{j}\right)$, or dependent of both effects either with interaction $\left(\beta_{i, j}\right)$ or without $\left(\beta 1_{i}+\beta 2_{j}\right)$. The best model was chosen by minimizing the Deviance Information Criterion (DIC), a Bayesian measure of fit adequacy, penalized by model complexity (Spiegelhalter et al., 2002; Plummer, 2009).

\section{Olfactometry bioassays}

We assumed that the presence of EO might only affect the probability for a parasitoid to stay in a given zone of the exposure chamber. In order to estimate this effect, we built a model that represents the parasitoids' distribution over the four zones throughout an experiment. The parameters of this model were determined with Bayesian inference (details are provided in the Supplementary Information S.4). We first analyzed control experiments to determine parasitoid movements in the absence of EO. Then, parameter estimates from this analysis of control experiments were used as priors in the analysis of subsequent treatment experiments. The model can be divided in four phases: (i) initial distribution of the individuals across the zones, (ii) determination of the individuals that stay in their current zone, (iii) determination of the flow of individuals coming from other zones, and (iv) update of the individuals' distribution across the zones.

Phase (i) At the beginning of an experiment (either a control or a treatment), parasitoids are randomly distributed in the exposure chamber. The exposure chamber is virtually separated between the four zones with air fields named $z(z \in\{1,2,3,4\})$ and all the strips between fields gather together and called $y$. With $\mu$ being the probability to be in $y$, the number of individuals at time $t=0$ in zone $z=1$ is $\mathrm{Nb}_{1}(0) \sim$ $\mathcal{B}$ in $\left(\operatorname{NbTotal}(0), \frac{1-\mu}{4}\right)$. Then, for each $z \in\{2,3,4\}, \operatorname{Nb}_{z}(0) \sim \mathcal{B}$ in $\left(\operatorname{NbTotal}(0)-\sum_{z^{\prime}<z} \operatorname{Nb}_{z^{\prime}}(0), \frac{1-\mu}{5-z}\right)$. The number of individuals in $y$ is thus $\mathrm{Nb}_{y}(0)=\operatorname{NbTotal}(0)-\sum_{z=1}^{4} \mathrm{Nb}_{z}(0)$. 
Phase (ii) In all experiments, a given proportion of parasitoids are assumed to stay in their zone during one minute. This proportion is modelled with an inverse logit function in order to stay in a $[0,1]$ interval. This proportion is squared for control experiments and cubed for treatment experiments, to make them comparable (since pictures are separated by respectively two and three minutes). In a control experiment, a proportion $\frac{1}{\left(1+e^{-\psi_{j}}\right)^{2}}$ of individuals (from strain $j$ ) stays two minutes in a given zone. The individuals that stay in a zone $z$ at time $t$ are thus $S_{z}(t) \sim \mathcal{B} i n\left(\mathrm{Nb}_{z}(t), \frac{1}{\left(1+e^{-\psi_{j}}\right)^{2}}\right), t \in\{0,2\}$. In a treatment experiment, the two zones without odor (namely zone 3 and 4) are similar to the control test. The only difference is that the pictures being taken each 3 minutes, the probability to stay in the odorless zone becomes $\frac{1}{\left(1+e^{-\psi_{j}}\right)^{3}}$. For $z \in\{3,4\}$, the individuals staying in the zone $z$ at time $t$ is thus $S_{z}(t) \sim \mathcal{B} \operatorname{in}\left(\mathrm{Nb}_{z}(t), \frac{1}{\left(1+e^{-\psi_{j}}\right)^{3}}\right), t \in\{0,3,6,9,12\}$. The other two zones contain respectively $10 \mu L$ (zone 1) and $5 \mu L$ (zone 2) of essential oil. The probability to stay in these two zones depends on the effect of essential oil $i$ on the parasitoids from strains $j$ such as $S_{1}(t) \sim \mathcal{B} i n\left(\mathrm{Nb}_{1}(t), \frac{1}{\left(1+e^{-\left(\psi_{j}+\omega_{i, j}\right)}\right)^{3}}\right)$, and $S_{2}(t) \sim \mathcal{B} i n\left(\mathrm{Nb}_{1}(t), \frac{1}{\left(1+e^{-\left(\psi_{j}+\lambda_{i, j}\right)}\right)^{3}}\right)$, with $t \in\{0,3,6,9,12\}$. Parameter $\omega_{i, j}$ and $\lambda_{i, j}$ respectively represent the effect of 10 and $5 \mathrm{~mL}$ of essential oil $i$ on strain $j$.

Phase (iii) In both control and treatment experiments, we assume that the parasitoids have enough time (either two or three minutes) to move freely in the exposure chamber. The individuals leaving a given zone are thus randomly distributed between the other zones. For control experiments, the flow of individuals arriving from a zone $z$ at time $t$ (with $t \in\{2,4\})$, is $\operatorname{from}_{z}(t)=\frac{1-\mu}{3}\left(\mathrm{Nb}_{z}(t-2)-S_{z}(t-2)\right)$. For treatment experiments, the flow of individuals arriving from a zone $z$ at time $t$ is $\operatorname{from}_{z}(t)=\frac{1-\mu}{3}\left(\mathrm{Nb}_{z}(t-3)-S_{z}(t-3)\right), t \in$ $\{3,6,9,12,15\}$. In both control and treatment experiments, the flow of individuals arriving from the excluded space $y$ is $\operatorname{from}_{y}(t)=\frac{1-\mu}{4}\left(\mathrm{Nb}_{y}\right)$, with $t \in\{2,4\}$ in control experiments and $t \in\{3,6,9,12,15\}$ in treatment experiments.

Phase (iv) The resulting number of individuals in a zone is obtained as the realization of a Poisson function depending on the sum of the number of staying individuals in this zone and the flows of individuals from all the other zones. In control experiments, the resulting number of individuals in a zone $z(z \in\{1,2,3,4\})$ at time $t(t \in\{2,4\})$, is $\mathrm{Nb}_{z}(t) \sim \mathcal{P}\left(S_{z}(t-2)+\sum_{z^{\prime} \neq z}\right.$ from $_{z^{\prime}}(t)+$ from $\left._{y}(t)\right)$. In treatment experiments, the resulting number of individuals in a zone $z(z \in\{1,2,3,4\})$ at time $t(t \in\{3,6,9,12,15\})$, is $\operatorname{Nb}_{z}(t) \sim$ $\mathcal{P}\left(S_{z}(t-3)+\sum_{z^{\prime} \neq z}\right.$ from $_{z^{\prime}}(t)+$ from $\left._{y}(t)\right)$. In both control and treatment experiments, the updated number of individuals in space $y$ is $\mathrm{Nb}_{y}(t)=\operatorname{NbTotal}(t)-\sum_{z=1}^{4} \mathrm{Nb}_{z}(t)$. Phases (ii)-(iv) are then repeated until reaching the final time ( $t=4$ for control experiments and $t=15$ for treatment experiments).

We first tested different kind of parameter $\psi_{j}$ to analyze data from control experiments with Bayesian inference. $\psi_{j}$ was either a constant $(\psi)$, or variable with strain $j\left(\psi_{j}\right)$, or specific for each experiments either around a constant value $\left(\psi_{k}\right)$ or strain-specific values $\left(\psi_{k(j)}\right)$ (Table 2$)$. We also checked that no bias existed due to the position by modeling a parameter dependent on the zone of the exposition chamber $\left(\psi_{z}\right)$. The pertinence of the whole model was tested by fitting a model $\psi_{-\infty}$ where no individuals stayed in the different zone and parasitoids were randomly distributed each time step. We relied on the DIC to identify the best control model. From this best control model, we extracted estimated values for parameters $\mu$ and $\psi_{j}$, and used them as priors to analyze data from treatment experiments with Bayesian inference (treatment models in Table 3). We tested different parameters $\lambda_{i, j}$ and $\omega_{i, j}$. $\omega$ was either equal to $\lambda_{i, j}$ (no concentration effect), or to $2 \lambda_{i, j}$ (linear concentration effect) or independent (non-linear concentration effect). Parameter $\lambda$ was either null, or dependent on essential oil without variation between strains $\left(\lambda_{i}\right)$, or dependent on essential oil with fixed variation between strains $\left(\lambda_{i, \sigma(j)}\right)$, or dependent on essential oil with a variance between strains dependent on 
essential oil $\left(\lambda_{i, \sigma_{i}(j)}\right)$. The best model was determined by minimizing the DIC. Details on Bayesian inference are available in Supplementary Information S.4.

\section{Results}

\section{Pre-imaginal survival}

A large majority of EOs were found to be highly toxic for T. evanescens (Fig 4). Indeed, the predicted $C_{50}$, the concentration at which half the parasitoid eggs do not develop into an adult (see Rosemary EO example, Fig 4.a), is less than $2 \mu L$ for most EOs (Fig 4.b). Rosemary, Sweet orange and Mugwort EOs seem less toxical since their $C_{50}$ are respectively $14 \pm 4 \mu L, 12 \pm 3 \mu L$ and $5 \pm 1 \mu L$ (mean and standard deviation of estimated $C_{50}$ between the five strains).

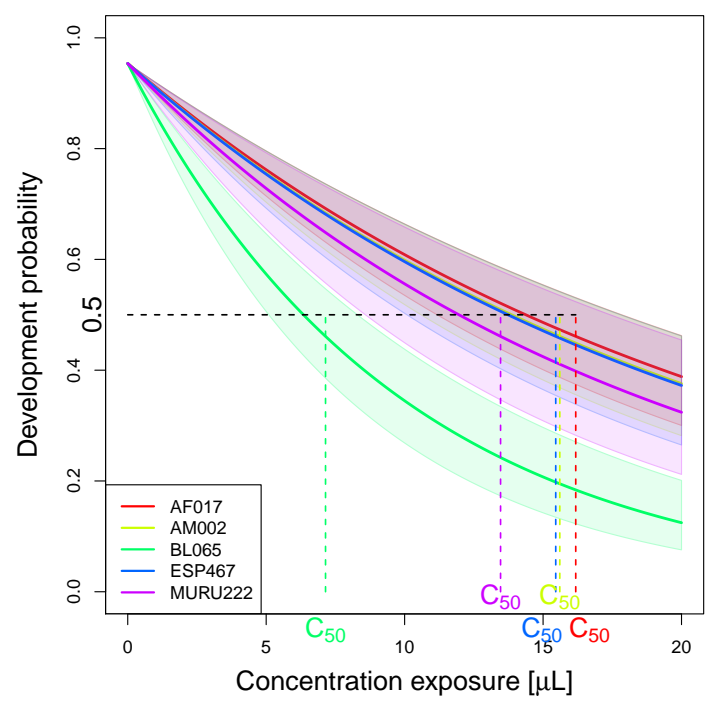

(a)

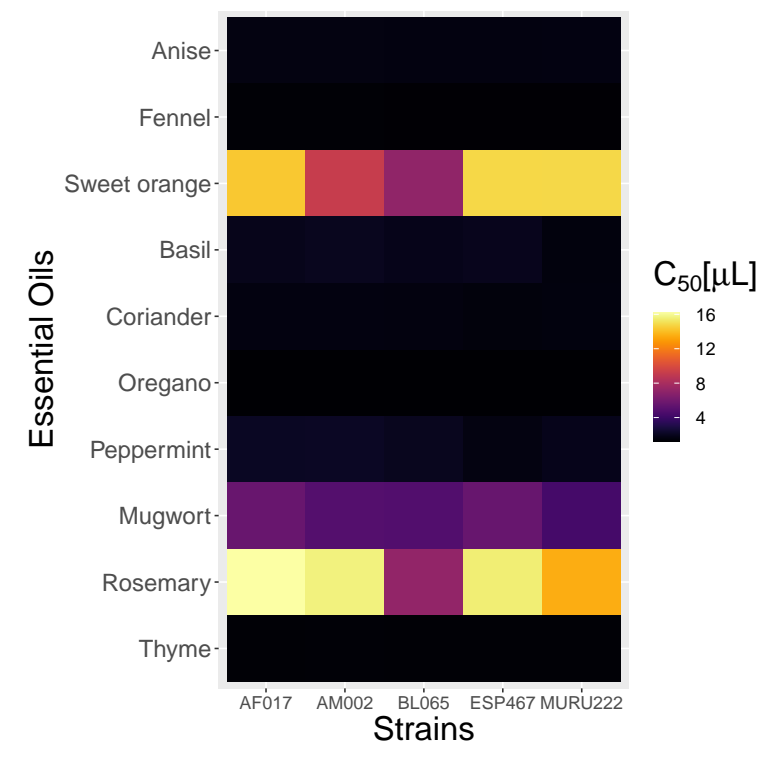

(b)

Figure 4: Effect of essential oils on the development probability of five strains of T. evanescens. (a) Predicted development probability for each strain according to Rosemary essential oil. Colors represent the different strains. Dashed lines are the $C_{50}$ projections, i.e. the concentration at which $50 \%$ of the eggs do not develop. Natural development probability is estimated from control experiment at $0.95 \pm .01$. (b) Predicted $C_{50}$ according to the different strains (columns) and essential oils (rows). Dark squares represent low $C_{50}$, meaning highly toxicity of a given essential oil for a given strain.

The flexibility of this Bayesian analysis allows to separate the toxicity on pre-pupal development (before egg darkening occurs ; $\alpha$ ) from the toxicity on pupal development (after the egg has darkened ; $\alpha+\beta$ ). According to the DIC, the best model takes into account $\alpha_{i, j}$ that depends on each combination EO x strain, and $\beta_{i}$ that only varies according to the essential oil (model 1 in Table 1).

Toxicity in the first phase of development is variable according to both EOs and strains (Fig 5.a). However, the amplitude of these variations are quite limited. Indeed, mean estimations of parameter $\alpha_{i, j}$ vary between $0.2 \cdot 10^{-3}$ (for strain AF017 with Rosemary essential oil) and $8.5 \cdot 10^{-3}$ (for strain MURU222 with Basil essential oil) according to EOs and strains (Fig 5.a). These values mean that the probability that parasitoids survive during the first five days is estimated between 0.79 and 0.98 for $5 \mu L$ of essential oil (with a natural daily survival probability estimated at $0.997 \pm .0005)$. The interaction between essential oil and strain effects 
Table 1: Pre-imaginal survival models according to their structures regarding parameters $\alpha$ (toxicity on egg and larval development) and $\beta$ (difference between pupae and first instars sensibility). (\#) is the number of estimated parameters. Tested models are ranked according to increasing DIC. $i$ and $j$ stand respectively for a given essential oil and Trichogramma strain.

\begin{tabular}{|lllll|}
\hline Model & $\alpha$ & $\beta$ & $\#$ & DIC \\
\hline $\mathbf{1}$ & $\alpha_{i, j}$ & $\beta 1_{i}$ & $\mathbf{6 7}$ & $\mathbf{7 7 0 1}$ \\
2 & $\alpha_{i, j}$ & $\beta_{i, j}$ & 107 & 7751 \\
3 & $\alpha_{i, j}$ & $\beta 1_{i}+\beta 2_{j}$ & 72 & 7778 \\
4 & $\alpha 1_{i}+\alpha 2_{j}$ & $\beta 1_{i}$ & 32 & 8395 \\
5 & $\alpha 1_{i}$ & $\beta_{i, j}$ & 67 & 8885 \\
6 & $\alpha 1_{i}+\alpha 2_{j}$ & $\beta 1_{i}+\beta 2_{j}$ & 37 & 8986 \\
7 & $\alpha_{i, j}$ & $\beta 2_{j}$ & 62 & 9444 \\
8 & $\alpha_{i, j}$ & 0 & 57 & 12416 \\
\hline
\end{tabular}

has to be taken into account $\left(\Delta \mathrm{DIC}_{\text {model.4,model.1 }}=694\right.$ in Table 1$)$. Despite this great variability, some broad patterns can be identified: on the one hand, Peppermint and Basil EOs appear particularly toxic for egg and larval development (Fig 5.a); on the other hand, strains AF017 and AM002 seem slightly less sensitive than other strains to essential oils in this first phase of development (Fig 5.a).

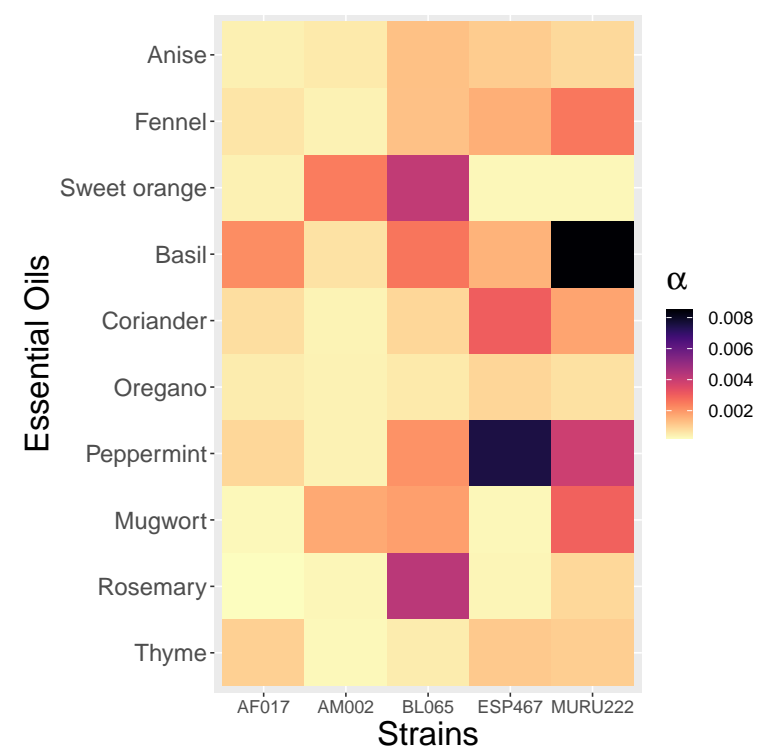

(a)

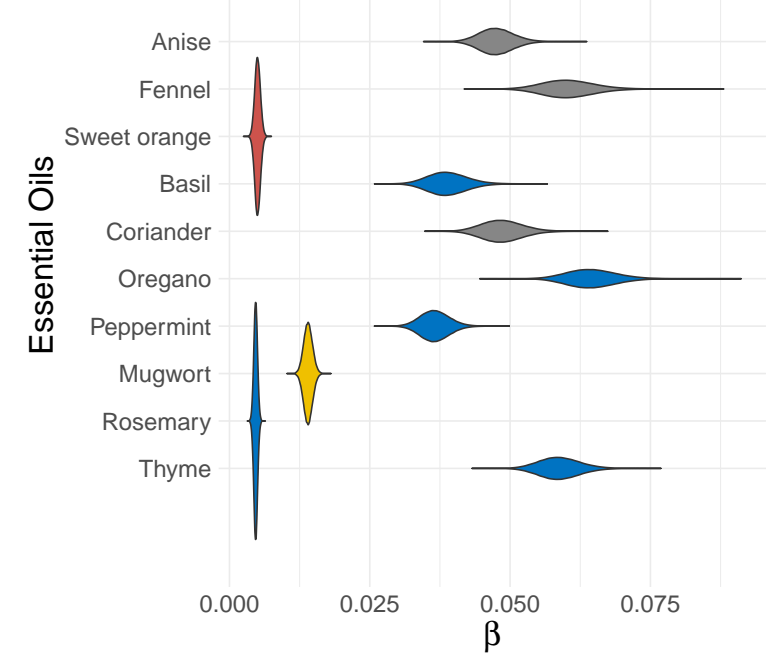

(b)

Figure 5: Estimations of parameters $\alpha_{i, j}$ (a) and $\beta_{i}$ (b) in model 1 from Table 1: (a) mean of the estimated posterior distribution of parameter $\alpha_{i, j}$ according to both the stains (columns) and the essential oils (rows). Darker squares stand for higher $\alpha_{i, j}$ and signify higher toxicity of a given essential oil for a given strain.; (b) estimated posterior distribution of parameter $\beta_{i}$ for each essential oil. Colors represent plant families: grey for Apiaceae, orange for Rutaceae, blue for Lamiaceae and yellow for Asteraceae. Higher values represent higher toxicity.

Either by accumulation effect or because of pupal higher sensitivity, EOs were more toxic on parasitoid development in the second (pupal) phase ( $\beta_{i}>0$ for all essential oil $i$, Fig 5.b). In this second phase, survival only depends on essential oil ( $\Delta \mathrm{DIC}_{\text {model.2,model.1 }}=50$ in Table 1$)$ and the effects can be quite drastic. Indeed, mean estimations of parameter $\beta_{i}$ vary between $4.7 \cdot 10^{-3}$ for Rosemary essential oil and $64.5 \cdot 10^{-3}$ for Oregano essential oil (Fig 5.b). These values mean an estimation of survival probability between 0.03 and 0.78 for $5 \mu L$ of essential oil for this second phase. Sweet orange, Rosemary, and to a lesser extend Mugwort seem less toxic 
than the other tested EOs (Fig 5.b).

\section{Olfactometry bioassays}

In control experiments, the probability to stay in a given zone of the olfactometer chamber did not depend neither on the strain, nor on the experiment, nor on the orientation of the experimental setup (replicate number), as desired (Table 2). Without any EO stimulus injected into the olfactometer chamber, the probability for a parasitoid to stay in a given zone for one minute was estimated around $0.85(\in[0.82,0.87])$.

Table 2: Control olfactory experiment models according to their structures regarding parameters $\psi$ determining the probability for an individual to stay in a given zone for $1 \mathrm{~min}$. (\#) is the number of estimated parameters. Models are ranked according to increasing DIC. $j, z$ and $k$ respectively stand for a given strain, zone or experiment.

\begin{tabular}{|llll|}
\hline Model & $\psi$ & $\#$ & DIC \\
\hline $\mathbf{1}$ & $\psi$ & $\mathbf{2}$ & $\mathbf{1 1 1 6 9}$ \\
2 & $\psi_{z}$ & 5 & 11171 \\
3 & $\psi_{k}$ & 3 & 11174 \\
4 & $\psi_{j}$ & 6 & 11176 \\
5 & $\psi_{k(j)}$ & 7 & 11185 \\
6 & $\psi_{-\infty}$ & 1 & 12885 \\
\hline
\end{tabular}

In treatment experiments, the distribution of individuals was strongly impacted by the presence of EOs $\left(\Delta \mathrm{DIC}_{\text {model.6,model.4 }}=528\right.$ in Table 3$)$ but did not depend on the dose of $\mathrm{EO}\left(\Delta \mathrm{DIC}_{\text {model.3,model. } 1}=51\right.$ and $\Delta$ DIC $_{\text {model.5,model.1 }}=160$ in Table 3$)$. The effect of EOs was variable across the different strains $\left(\Delta\right.$ DIC $_{\text {model.4,model.2 }}=72$ in Table 3 ). Moreover, the inter-strain variance was also dependent on essential oils $\left(\Delta \mathrm{DIC}_{\text {model.2,model.1 }}=3\right.$ in Table 3$)$. The effect of EOs estimated for each strain might be highly variable (Fig 6).

Table 3: Treatment olfactory experiment models according to their structures regarding parameters $\lambda$ (odor effect with $5 \mathrm{~mL}$ of essential oil) and $\omega$ (odor effect with $10 \mathrm{~mL}$ of essential oil). (\#) is the number of estimated parameters. Models are ranked according to increasing DIC. $i$ and $j$ stand respectively for a given essential oil and strain.

\begin{tabular}{|lllll|}
\hline Model & $\lambda$ & $\omega$ & \# & DIC \\
\hline $\mathbf{1}$ & $\lambda_{i, \sigma_{i}(j)}$ & $\lambda_{i, \sigma_{i}(j)}$ & $\mathbf{2 2}$ & $\mathbf{2 3 1 9 2}$ \\
2 & $\lambda_{i, \sigma(j)}$ & $\lambda_{i, \sigma(j)}$ & 13 & 23195 \\
3 & $\lambda_{i, \sigma_{\lambda}(j)}$ & $\omega_{i, \sigma_{\omega}(j)}$ & 42 & 23243 \\
4 & $\lambda_{i}$ & $\lambda_{i}$ & 12 & 23267 \\
5 & $\lambda_{i, \sigma_{i}(j)}$ & $2 \cdot \lambda_{i, \sigma_{i}(j)}$ & 22 & 23352 \\
6 & 0 & 0 & 2 & 23795 \\
\hline
\end{tabular}

The presence of Basil, Coriander, Peppermint, Mugwort or Thyme EO tended to repel all strains (red squares in Fig 6). Indeed, negative values of $\lambda_{i, j}$ mean that the probability to stay in a zone with odor was lowered by the presence of EO. As a result, the numbers of parasitoids in the zones containing odor drastically declined through time (Fig 7.a). For these five EOs, the posterior distribution of the average effect was clearly shifted to negative values $(<0.05 \%$ of positive values in Fig 8$)$

For Anise, Fennel, Sweet orange, Oregano or Rosemary, the impact on parasitoid behavior qualitatively differed between strains (Fig 6). On average, their presence decreased the probability for parasitoids to stay in a zone with odor. However, the posterior distribution of the average effect included 0 (Fig 8.a). Their presence 


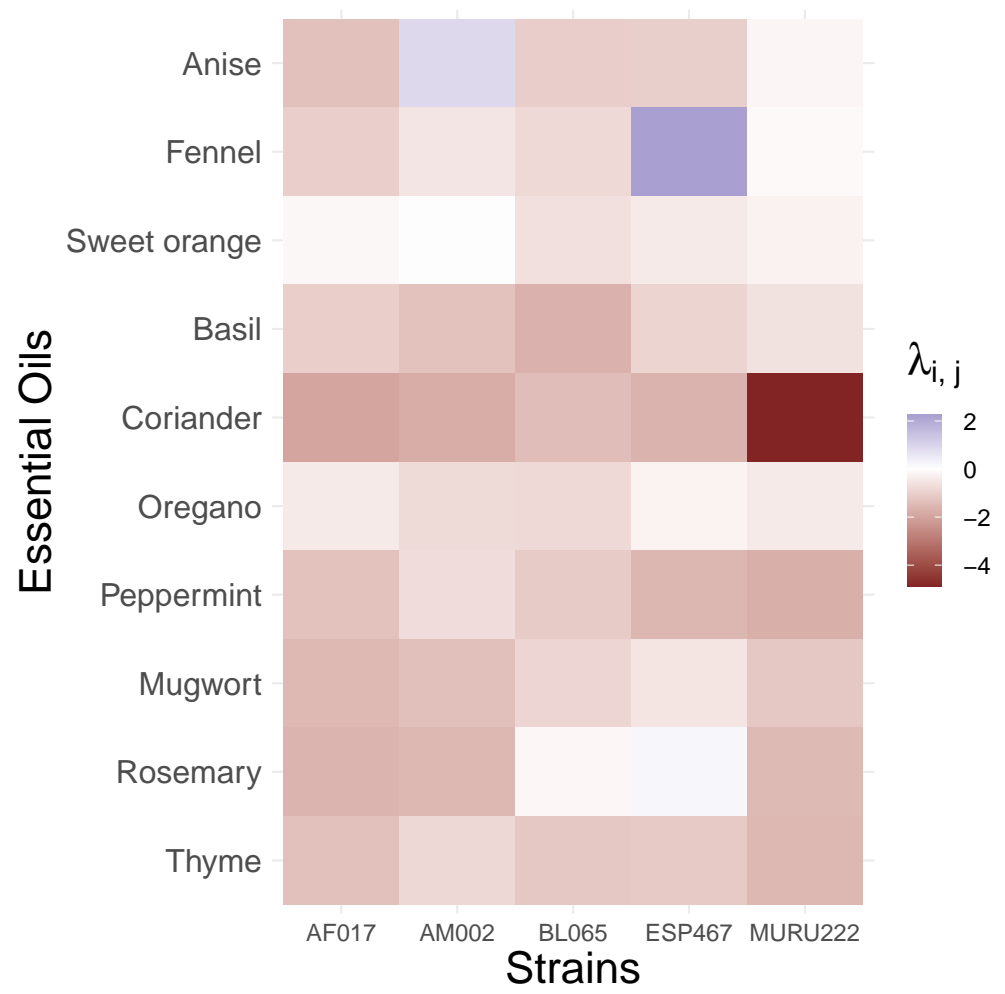

Figure 6: Effect of Essential Oils (rows) on the orientation of different strains of T. evanescens (columns). Parameter $\lambda_{i, j}$ represent the effect of a given essential oil on the probability, for a parasitoid of a given strain, to stay in the same odor zone. Reddish and blueish squares respectively represent repulsion and attraction of a given strain for a given Essential Oil. The darker the square, the more intense is estimated the effect.

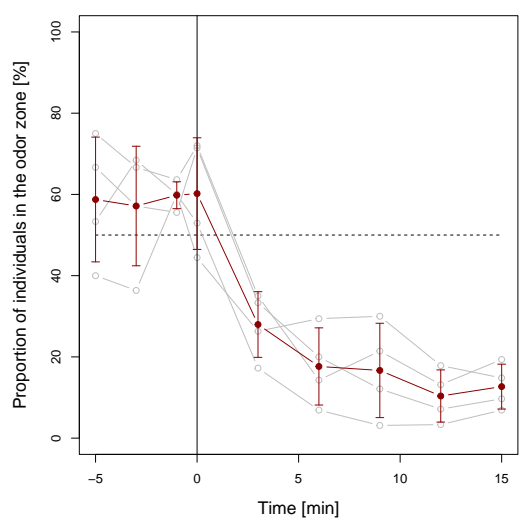

(a)

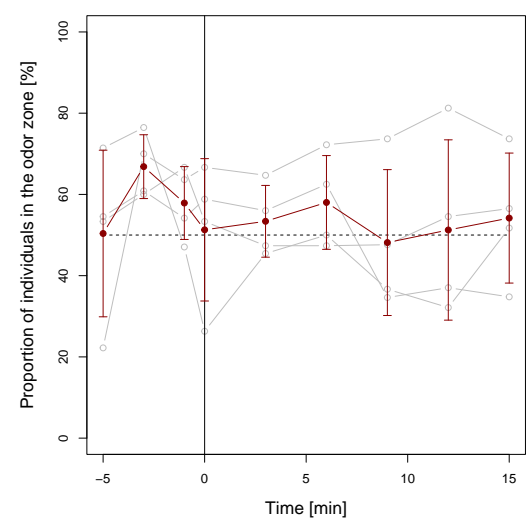

(b)

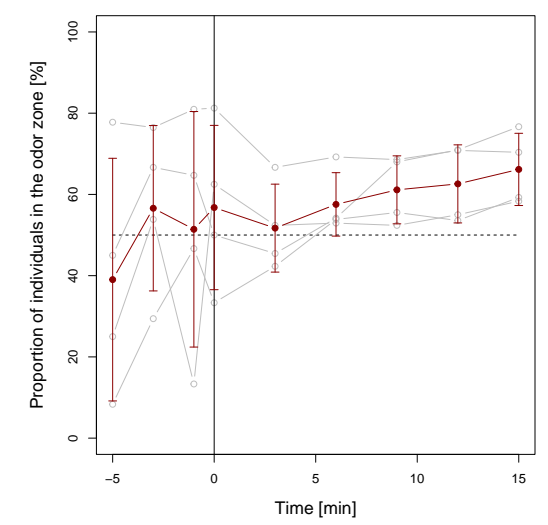

(c)

Figure 7: Proportion of individuals in the zone with odor during the experiment: (a) Coriander essential oil and MURU222 strain; (b) Sweet orange essential oil and AM002 strain; (c) Fennel essential oil and ESP467 strain. The black vertical bar represents the introduction of odor. Dashed line symbolize the random distribution (50\% individuals). The four replicates are represented by the grey broken lines and summarized by their mean and standard deviation with the dark red broken lines and error bars. 


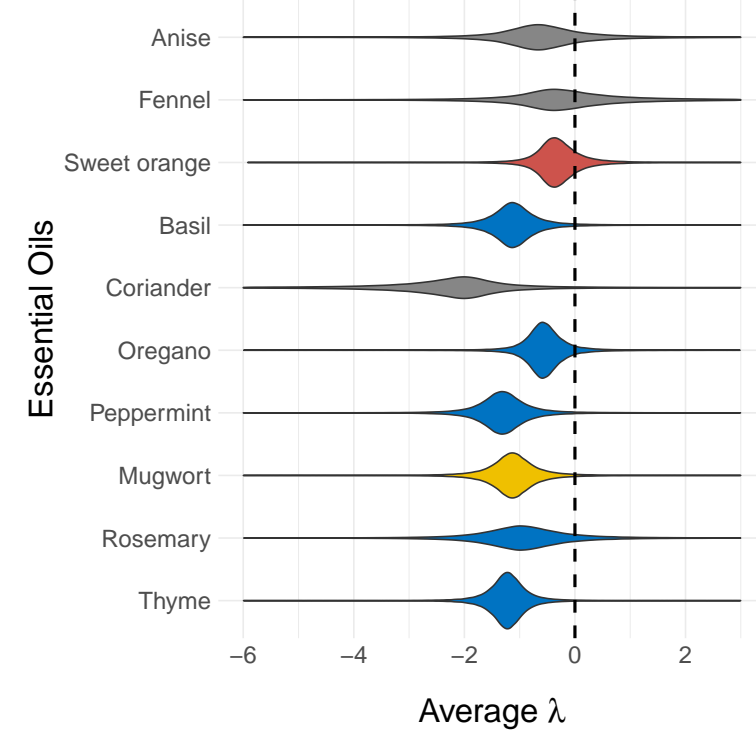

(a)

could thus be almost neutral (white squares in Fig 6) and results in a nearly homogeneous distribution in the experimental setup (Fig 7.b). For both Anise and Fennel EOs, parameter $\lambda_{i, j}$ were actually estimated as positive for at least one strain $j$ (blue squares in Fig 6). This attractive effect resulted in an increasing proportion of individuals in the odor zones throughout the experiments (Fig 7.c).

Inter-strain variability was important. Three scenarios, defined by the shape of the posterior distribution of the EO-specific inter-strain variance (Fig 8.b), can be recognized: (i) For Sweet orange, Oregano and Thyme, inter-strain variance is very low (estimated mean of inter-strain variance $<1.6$ ) and the effect of EOs on parasitoid behavior is very consistent for all tested strains. (ii) For Basil, Peppermint and Mugwort, results are slightly different between strains (estimated mean of inter-strain variance $\in[1.6,2.3]$ ); and (iii) For Anise, Fennel, Coriander and Rosemary EOs, the variability of effect according to the tested strains is considerable (estimated mean of inter-strain variance $>6$ ). There were different result across strains either quantitatively (for Coriander EO), or even qualitatively (for Anise, Fennel and Rosemary EOs).

Figure 8: Estimated posterior distribution of the essential oil specific (a) mean $\left(m_{\lambda(i)}\right)$ and (b) inter-strain variance $\left(v_{\lambda(i)}\right)$ used to define parameter $\lambda_{i, j}$ in model 1 from Table 3. Colors represent plant families: grey for Apiaceae, orange for Rutaceae, blue for Lamiaceae and yellow for Asteraceae. (a) Negative and positive values respectively represent global repulsiveness and attraction of a given Essential Oil. (b) Higher values mean larger differences in the essential oils effect between strains.

There was no correlation between the effect of EOs on parasitoid behavior and their toxicity on individual

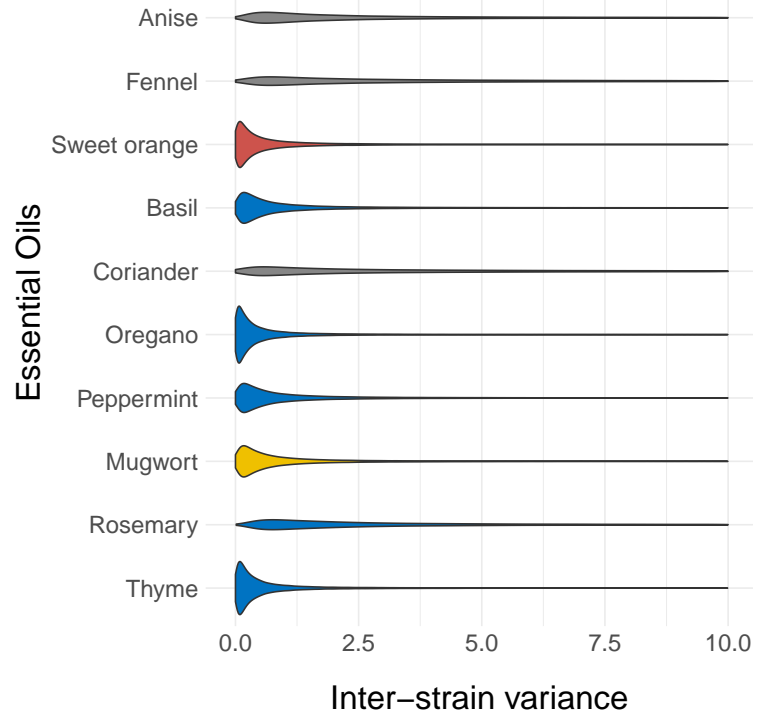

(b) development (Fig 9; Pearson $\mathrm{t}(48)=0.63, \mathrm{p}=0.53$ ). We expected that the more toxic EOs might provoke greater avoidance and thus be more repellent. Consistent with this expectation, EOs with low toxicity (Rosemary and Sweet Orange) showed little impact on parasitoid distribution. Similarly, some of the highly toxic EOs (Basil, Coriander, Peppermint and Thyme) were highly repellent. However, both Anise and Fennel EOs, that are highly toxic for parasitoid development, provoked no avoidance behavior, and for some strains, even appeared to be attractive (Fig 9). 


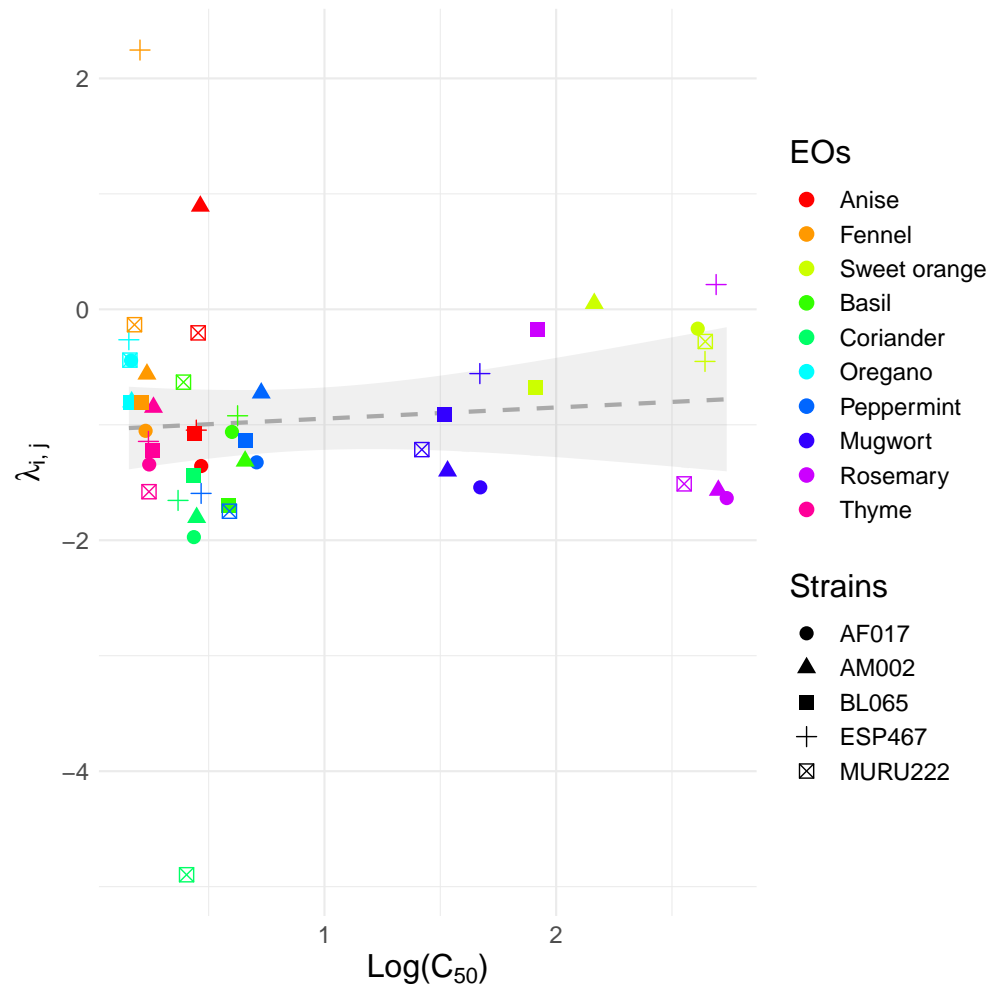

Figure 9: Lack of correlation between attraction and toxicity for the different essential oils (colors) and strains (symbols) tested. Attraction is represented by parameter $\lambda_{i, j}$ (see Fig 6). Toxicity on pre-imaginal developement is showed by the logarithm of the predicted $C_{50}$ (i.e. the concentration, in $\mu \mathrm{L}$, at which $50 \%$ of the eggs do not emerge). Grey dashed line (and shadow) represent the estimation of a non-significant linear model (and standard error).

\section{Discussion}

We tested both direct and indirect non-target effects of 10 essential oils (EOs) potentially used as biopesticides. These EOs all affected $T$. evanescens development, with some variability in the severity of their impact. Regarding the movement patterns of trichogramma adults, the majority of EOs had a repellent effect for naive females. In a few cases, however, the EOs seemed either neutral or even had a slight attractive effect. These results might be summarized by describing five groups of EOs (Table 4): (i) low effects: Rosemary and Sweet Orange EOs show low toxicity on parasitoids development and hardly no impact on orientation behavior; (ii) intermediate effects: Mugwort essential oil is moderately toxic and seem repellent for naive females; (iii) contrasting effects: Oregano essential oil is highly toxic yet has almost no discernible effect on parasitoid behavior; (iv) variable effects: Anise and Fennel EOs are highly toxic for parasitoid development and can have repellent to attractive effect on females depending on strains; (v) strong effects: Basil, Coriander, Peppermint and Thyme EOs are highly toxic and invariably very repellent for T. evanescens.

Pure EOs displayed fumigant toxicity on T. evanescens development. Indeed, all the tested EOs reduced the emergence rate of parasitized eggs. Anise, Fennel, Basil, Coriander, Oregano, Peppermint and Thyme appeared particularly toxic since they drastically reduced pre-imaginal development, even at low concentration. The insecticidal potential of these EOs on non-target insects such as parasitoids is thus confirmed (RegnaultRoger, 1997; Sampson et al., 2005; Rani and Sandhyarani, 2012; Mossa, 2016). Some EOs are reported to act as Insect Growth Regulators and disrupt insect developement by inhibiting biosynthetic processes at different growth stages, thus reducing adults emergence (Agarwal et al., 2001; Kumar et al., 2011; Mossa, 2016). In Tri- 
Table 4: Summary of the results obtained regarding the toxicity of 10 EOs on T. evanescens pre-imaginal development and their effect on parasitoid orientation. Colors represent plant families: cyan for Apiaceae, grey for Asteraceae, magenta for Lamiaceae and orange for Rutaceae.

\begin{tabular}{|l|l|l|l|}
\hline Orientation Toxicity & low & medium & high \\
\hline No impact & $\begin{array}{l}\text { Rosemary } \\
\text { Sweet Orange }\end{array}$ & & Oregano \\
\hline Variable among strains & & & $\begin{array}{l}\text { Anise } \\
\text { Fennel }\end{array}$ \\
\hline Repellent & & Mugwort & $\begin{array}{l}\text { Basil } \\
\text { Coriander } \\
\text { Peppermint } \\
\text { Thyme }\end{array}$ \\
\hline
\end{tabular}

chogramma embryophagum (Hartig) and T. evanescens, exposition of pre-imaginal stages to Ferula assfoetida essential oil increases pre-imaginal development time, decreases emergence rate and increases drastically wing abnormality among the emerged adults (Poorjavad et al., 2014). In our Bayesian analyses, we found that the impact on the second phase of development (pupal stages) was stronger than on the first phase (egg-larval stages). That could either be explained by a non-linear accumulation effect of fumigant toxicity over time (for instance because of slow diffusion through host tissues). It could also confirm that pupal stages are more sensitive to exposition to EOs in Trichogramma (Parreira et al., 2018a,b). Indeed, the emergence of parasitized eggs of $E$. kuehniella was not affected by a five-second immersion in diluted EOs during the egg/larva stage ( $<1$ day after parasitism) while it was reduced by more than $30 \%$ when immersion occurred at the pupal stage (7-8 days after parasitsm) for T. pretiosum (Parreira et al., 2018a) and T. galloi (Parreira et al., 2018b).

Sweet Orange and Rosemary EOs were almost innocuous on pre-imaginal development. This difference is probably accountable by the mode of action of the main chemical compounds of these oils. Indeed, Rosemary EO is mainly composed of 1,8-cineole (or eucalyptol) (Suppl. Inf. S.1, see also (Isikber et al., 2006; Isman et al., 2008)). 1,8-cineole is known to inhibit the activity of acetylcholinesterase (AChE), an enzyme present in neuro-neuronal and neuro-muscular junctions (Mills et al., 2004; Jankowska et al., 2018). AChE inhibition causes paralisis and death of insects (Ryan and Byrne, 1988). At low concentration, Rosemary essential oil may thus have little growth inhibition effet on Trichogramma as it was shown on beetles (Isikber et al., 2006) or noctuid caterpillars (Akhtar et al., 2008). Nevertheless, Rosemary EO is particularly toxic on adult stages (Isikber et al., 2006; Isman et al., 2008; Hanane et al., 2018). Moreover, both Citrus aurantium and Rosemarinus officinaly also repel phytophagous insects (Hori, 1998; Saeidi et al., 2011).

Most tested EOs affected the behavior of T. evanescens by increasing the probability to leave the odor zone of the olfactometer. Basil, Coriander, Peppermint, Mugwort or Thyme EOs seem particularly repellent for all tested strains. A repellent activity of EOs was recently documented in two Trichogramma species (Parreira et al., 2019; Alcántara-de la Cruz et al., 2021). In T. pretiosum (Parreira et al., 2019) and T. galloi (Alcántarade la Cruz et al., 2021), previous exposition of host eggs to Zingiber officinale, Allium sativum and Carapa guianensis EOs, respectively, inhibited or drastically reduced parasitism rate. For both parasitoids, Citrus sinensis, M. piperita, $O$. vulgare or T. vulgaris did not affect parasitism rate in this non-choice situation (Parreira et al., 2019; Alcántara-de la Cruz et al., 2021). In contrast, in our experimental setup, where individuals might choose either to be directly exposed to pure EOs or to escape and stay in an odorless zone, Peppermint and Thyme proved to be very repellent. The concentration used might also contribute to explain those differences: in our experimental conditions, the lack of difference between $5 \mu \mathrm{L}$ or $10 \mu \mathrm{L}$ zones suggests that the odor airflow 
is probably very charged in EOs from the parasitoid perspective. On the contrary, a past exposition of host eggs to respectively four and two $\mu L$ of Peppermint and Thyme EOs diluted in ethanol might not be so repulsive for parasitoids. Tested on the egg parasitoid Trissolcus basalis, three-day residues of pure T. vulgaris decreased parasitism rate while seven-day residues had no effect on parasitoid behavior (González et al., 2013). The effect of residues may thus decrease with both concentration and time.

The importance of inter-strain variability was particularly striking regarding orientation behavior (Milonas et al., 2009). Indeed, for Fennel, Anise, Sweet orange, Oregano and Rosemary EOs, the response of parasitoids was qualitatively different across strains. Some strains were repelled while other were indifferent, or even slightly attracted, by Anise and Fennel EOs. The main chemical compound of both Anise and Fennel EOs is anethole (Suppl. Inf. S.1). Anethole has biopesticidal potential (Sousa et al., 2021), and can be attractant for some insects such as scarabs (Toth et al., 2003) or lovebugs (Cherry, 1998). Anethole could thus act as an attractant for some strains of T. evanescens. However, strain AM002 was slightly attracted by Anise and slightly repelled by Fennel while ESP467 was attracted by Fennel and repelled by Anise. The effect of chemical composition on behavior must thus be more complex than the mere presence/absence of a single compound. Inter-strain variation might also result from the local adaptation of foraging behavior to different environmental conditions and host plants (Vos and Hemerik, 2003; Tamo et al., 2006).

A noteworthy facet of our experimental design is that parasitoid females were less than two days old, had probably mated (since they were reared with males), but had no oviposition experience. They had never been exposed to any olfactory stimulus except those from the substitute host from which they emerged (15-day old irradiated eggs of E. kueniella). Previous experiments on laboratory-reared T. evanescens showed that inexperienced females were not attracted to the synthetic sex pheromone of their hosts, contrary to females with previous oviposition experience (Schöller and Prozell, 2002). If some species of Trichogramma that were reared on factitious hosts were able to respond innately to native host cues (Milonas et al., 2009; Geetha, 2010), previous oviposition experience seems important for responding to olfactory signals (Kaiser et al., 1989; Fatouros et al., 2005; Consoli et al., 2010; Wilson and Woods, 2016). In this study, most EOs elicited escape behaviors in naive laboratory-reared females. This response might of course correspond to the avoidance of toxic compounds, but could also be induced by the perception of a strong unidentified olfactory stimulus, resulting in fear and avoidance due to neophobia (Corey, 1978). For generalist egg parasitoids such as Trichogramma, foraging decisions might greatly depend on learning abilities and on how infochemicals are linked to previous experience (Vet and Dicke, 1992; Wajnberg and Colazza, 2013; van Oudenhove et al., 2017).

This study confirms that fumigant application of EOs can have negative non-target effects on egg parasitoids T. evanescens, be it through mortality or repulsion (Poorjavad et al., 2014). IPM programs must thus be extremely cautious in how and when to apply EOs if the program integrate biological control with parasitoids (González et al., 2013; Dunan et al., 2021). Indeed, EOs jeopardize the success of natural regulation by direct or indirect effects on natural enemy fitness. This study also sets out possibilities for biocontrol programs that integrate semiochemicals to optimize the efficiency of egg parasitoids in an agroecosystems (Wajnberg and Colazza, 2013). The potential of attraction of Anise and Fennel EOs one the one hand and the repulsion of $T$. evanescens for Basil, Coriander, Peppermint, Mugwort or Thyme EOs on the other hand might give clues for defining "push-pull" strategies based on the manipulation of natural enemies behavior with living plant or plant extracts (Khan et al., 2006). 


\section{Acknowledgements}

We warmly thank Lydia Ottenwaelder for her help in some toxicity experiments. We are grateful to Robin Laugier for estimating T. evanescens sex-ratio. We thank Mélina Cointe for helpful discussions and comments. This work was financially supported by INRAE's Department of Plant Health and Environment and the Université Côte d'Azur (IDEX “Investissements d'Avenir UCAJEDI", project reference ANR-15-IDEX-01). The Trichogramma strains were provided by the Biological Resource Center EP-Coll that is a part of BRC4Env, the pillar "Environmental Resources" of the Research Infrastructure AgroBRC-RARe.

\section{References}

Agarwal, M., Walia, S., Dhingra, S., and Khambay, B. P. S. (2001). Insect growth inhibition, antifeedant and antifungal activity of compounds isolated/derived from zingiber officinale roscoe (ginger) rhizomes. Pest Management Science: formerly Pesticide Science, 57(3):289-300.

Akhtar, Y., Yeoung, Y.-R., and Isman, M. (2008). Comparative bioactivity of selected extracts from meliaceae and some commercial botanical insecticides against two noctuid caterpillars, trichoplusia ni and pseudaletia unipuncta. Phytochemistry reviews, 7(1):77-88.

Alcántara-de la Cruz, R., Parreira, D. S., Dimaté, F. A. R., Batista, L. D., Ribeiro, R. C., and Zanuncio, J. C. (2021). Effects of essential oils on biological attributes of trichogramma galloi adults. Journal of Asia-Pacific Entomology, 24(2):64-67.

Altieri, M. A., Annamalai, S., Katiyar, K. P., and Flath, R. A. (1982). Effects of plant extracts on the rates of parasitization of anagasta kuehniella [lep.: Pyralidae] eggs by trichogramma pretiosum [hym.: Trichogrammatidae] under greenhouse conditions. BioControl, 27(4):431-437.

Ananthakrishnan, T., Senrayan, R., Murugesan, S., and Annadurai, R. (1991). Kairomones of heliothis armigera and corcyra cephalonica and their influence on the parasitic potential of trichogramma chilonis (trichogrammatidae: Hymenoptera). Journal of biosciences, 16(3):111-119.

BAI, S.-x., WANG, Z.-y., HE, K.-1., and Im, D.-j. (2011). Olfactory response of trichogramma ostriniae (hymenoptera: Trichogrammatidae) to volatiles emitted by mungbean plants. Agricultural Sciences in China, 10(4):560-565.

Baricevic, C., Milevoj, L., and Borstnik, J. (2001). Insecticidal effect of oregano (origanum vulgare 1. ssp. hirtum ietswaart) on bean weevil (acanthoscelides obtectus say). International Journal of Horticultural Science, 7(2):84-88.

Bedini, S., Bougherra, H. H., Flamini, G., Cosci, F., Belhamel, K., Ascrizzi, R., Conti, B., et al. (2016). Repellency of anethole-and estragole-type fennel essential oils against stored grain pests: the different twins. Bull Insectol, 69(1):149-57.

Boo, K. and Yang, J. (1998). Olfactory response of trichogramma chilonis to capsicum annuum. Journal of Asia-Pacific Entomology, 1(2):123-129.

Burte, V., Perez, G., Ayed, F., Groussier, G., Mailleret, L., van Oudenhove, L., and Calcagno, V. (2022). Up and to the light: intra-and interspecific variability of photo-and geo-tactic oviposition preferences in genus trichogramma. Peer Community Journal, 2:e3. 
Cherry, R. (1998). Attraction of the lovebug, plecia nearctica (diptera: Bibionidae) to anethole. The Florida Entomologist, 81(4):559-562.

Consoli, F. L., Parra, J. R., and Zucchi, R. A. (2010). Egg parasitoids in agroecosystems with emphasis on Trichogramma, volume 9. Springer Science \& Business Media.

Corey, D. T. (1978). The determinants of exploration and neophobia. Neuroscience \& Biobehavioral Reviews, 2(4):235-253.

Dunan, L., Malanga, T., Bearez, P., Benhamou, S., Monticelli, L. S., Desneux, N., Michel, T., and Lavoir, A.-V. (2021). Biopesticide evaluation from lab to greenhouse scale of essential oils used against macrosiphum euphorbiae. Agriculture, 11(9):867.

Fatouros, N. E., Bukovinszkine'Kiss, G., Kalkers, L. A., Gamborena, R. S., Dicke, M., and Hilker, M. (2005). Oviposition-induced plant cues: do they arrest Trichogramma wasps during host location? Entomologia Experimentalis et Applicata, 115(1):207-215.

Fatouros, N. E., Lucas-Barbosa, D., Weldegergis, B. T., Pashalidou, F. G., van Loon, J. J. A., Dicke, M., Harvey, J. A., Gols, R., and Huigens, M. E. (2012). Plant volatiles induced by herbivore egg deposition affect insects of different trophic levels. Plos ONE, 7(8). A77.

Frenoy, C., Durier, C., and Hawlitzky, N. (1992). Effect of kairomones from egg and female adult stages of ostrinia nubilalis (hübner)(lepidoptera, pyralidae) on trichogramma brassicae bezdenko (hymenoptera, trichogrammatidae) female kinesis. Journal of chemical ecology, 18(5):761-773.

Geetha, N. (2010). Recognition of native host volatiles by laboratory reared trichogramma chilonis ishii. Journal of Biological Control, 24(2):126-132.

González, J. O. W., Laumann, R. A., Da Silveira, S., Moraes, M. C. B., Borges, M., and Ferrero, A. A. (2013). Lethal and sublethal effects of four essential oils on the egg parasitoids trissolcus basalis. Chemosphere, 92(5):608-615.

Haddi, K., Turchen, L. M., Viteri Jumbo, L. O., Guedes, R. N., Pereira, E. J., Aguiar, R. W., and Oliveira, E. E. (2020). Rethinking biorational insecticides for pest management: Unintended effects and consequences. Pest management science, 76(7):2286-2293.

Hanane, S. N., Benchaben, H., Mira, S., and M'Hamed, M. (2018). Insecticide effect of pennyroyal and rosemary essential oils on the rice weevil. Ukrainian Journal of Ecology, 8(1).

Hassan, S. A. (1993). The mass rearing and utilization of trichogramma to control lepidopterous pests: achievements and outlook. Pesticide Science, 37(4):387-391.

Hori, M. (1998). Repellency of rosemary oil against myzus persicae in a laboratory and in a screenhouse. Journal of Chemical Ecology, 24(9):1425-1432.

Ilboudo, Z. (2009). Activité Biologique de quatre huiles essentielles contre Callosobruchus maculatus Fab.(Coleoptera: Bruchidae), insecte ravageur des stocks de niébé au Burkina Faso. PhD thesis, Université de Ouagadougou.

Isikber, A., Alma, M., Kanat, M., and Karci, A. (2006). Fumigant toxicity of essential oils fromlaurus nobilis androsmarinus officinalis against all life stages oftribolium confusum. Phytoparasitica, 34(2):167. 
Isman, M. B. (2020). Botanical insecticides in the twenty-first century - fulfilling their promise? Annual Review of Entomology, 65:233-249.

Isman, M. B., Wilson, J. A., and Bradbury, R. (2008). Insecticidal activities of commercial rosemary oils (rosmarinus officinalis.) against larvae of pseudaletia unipuncta. and trichoplusia ni. in relation to their chemical compositions. Pharmaceutical Biology, 46(1-2):82-87.

Jankowska, M., Rogalska, J., Wyszkowska, J., and Stankiewicz, M. (2018). Molecular targets for components of essential oils in the insect nervous system - a review. Molecules, 23(1):34.

Kaiser, L. (1988). Plasticité comportementale et rôle des médiateurs chimiques dans la sélection de l'hôte par Trichogramma Maidis Pint. Et Voeg.:(hym. Trichogrammatidae). PhD thesis, Paris 11.

Kaiser, L., Pham-Delegue, M.-H., Bakchine, E., and Masson, C. (1989). Olfactory responses of trichogramma maidis pint, et voeg.: effects of chemical cues and behavioral plasticity. Journal of Insect Behavior, 2(5):701712 .

Khan, Z., Hassanali, A., and Pickett, J. (2006). Managing polycropping to enhance soil system productivity: a case study from africa. Biological approaches to sustainable soil systems, pages 575-586.

Kumar, P., Mishra, S., Malik, A., and Satya, S. (2011). Repellent, larvicidal and pupicidal properties of essential oils and their formulations against the housefly, musca domestica. Medical and Veterinary Entomology, 25(3):302-310.

Lewis, W., Jones, R. L., Nordlund, D. A., and Sparks, A. (1975). Kairomones and their use for management of entomophagous insects: I. evaluation for increasing rates of parasitization by trichogramma spp. in the field. Journal of chemical ecology, 1(3):343-347.

Mills, C., Cleary, B. V., Walsh, J. J., and Gilmer, J. F. (2004). Inhibition of acetylcholinesterase by tea tree oil. Journal of Pharmacy and Pharmacology, 56(3):375-379.

Milonas, P., Martinou, A., Kontodimas, D. C., Karamaouna, F., and Konstantopoulou, M. (2009). Attraction of different trichogramma species to prays oleae sex pheromone. Annals of the Entomological Society of America, 102(6):1145-1150.

Morey, R. A. and Khandagle, A. J. (2012). Bioefficacy of essential oils of medicinal plants against housefly, musca domestica 1. Parasitology research, 111(4):1799-1805.

Mossa, A.-T. H. (2016). Green pesticides: Essential oils as biopesticides in insect-pest management. Journal of environmental science and technology, 9(5):354.

Nerio, L. S., Olivero-Verbel, J., and Stashenko, E. (2010). Repellent activity of essential oils: a review. Bioresource technology, 101(1):372-378.

Noldus, L., Lewis, W., and Tumlinson, J. (1990). Beneficial arthropod behavior mediated by airborne semiochemicals. ix. differential response of trichogramma pretiosum, an egg parasitoid of heliothis zea, to various olfactory cues. Journal of Chemical Ecology, 16(12):3531-3544.

Parreira, D. S., Alcántara-de la Cruz, R., Dimaté, F. A. R., Batista, L. D., Ribeiro, R. C., Ferreira, G. A. R., and Zanuncio, J. C. (2019). Bioactivity of ten essential oils on the biological parameters of trichogramma pretiosum (hymenoptera: Trichogrammatidae) adults. Industrial Crops and Products, 127:11-15. 
Parreira, D. S., Alcántara-de la Cruz, R., Leite, G. L. D., de Souza Ramalho, F., Zanuncio, J. C., and Serrão,

J. E. (2018a). Quantifying the harmful potential of ten essential oils on immature trichogramma pretiosum stages. Chemosphere, 199:670-675.

Parreira, D. S., Alcántara-de la Cruz, R., Zanuncio, J. C., Lemes, P. G., da Silva Rolim, G., Barbosa, L. R., Leite, G. L. D., and Serrão, J. E. (2018b). Essential oils cause detrimental effects on biological parameters of trichogramma galloi immatures. Journal of Pest Science, 91(2):887-895.

Pavela, R. and Benelli, G. (2016). Essential oils as ecofriendly biopesticides? challenges and constraints. Trends in plant science, 21(12):1000-1007.

Peñaflor, M. F. G. V., Erb, M., Miranda, L. A., Werneburg, A. G., and Bento, J. M. S. (2011). Herbivoreinduced plant volatiles can serve as host location cues for a generalist and a specialist egg parasitoid. Journal of Chemical Ecology, 37(12):1304-1313.

Perez, G., Burte, V., Baron, O., and Calcagno, V. (2017). Une méthode d'analyse d'image automatique pour quantifier rapidement les nombres d'œufs et les taux de parasitisme chez trichogramma sp. Cahiers techniques de l'INRA. Innovations entomologiques: du laboratoire au champ, pages 135-142.

Pettersson, J. (1970). An aphid sex attractant. Insect Systematics \& Evolution, 1(1):63-73.

Pintureau, B. (2009). La lutte biologique et les trichogrammes. Application au contrôle de la pyrale du maïs. Editions Le Manuscrit.

Plummer, M. (2009). rjags: Bayesian graphical models using mcmc. $R$ package version 1.0.3-12, http://CRAN.R-project.org/package=rjags.

Poorjavad, N., Goldansaz, S. H., Dadpour, H., et al. (2014). Effect of ferula assafoetida essential oil on some biological and behavioral traits of trichogramma embryophagum and t. evanescens. Biocontrol, 59(4):403413.

Price, P. W. (1975). Evolutionary Strategies of Parasitic Insects. Springer.

R Core Team (2020). R: A Language and Environment for Statistical Computing. R Foundation for Statistical Computing, Vienna, Austria.

Rani, P. U., Kumari, S. I., Sriramakrishna, T., and Sudhakar, T. R. (2007). Kairomones extracted from rice yellow stem borer and their influence on egg parasitization by trichogramma japonicum ashmead. Journal of chemical ecology, 33(1):59-73.

Rani, P. U. and Sandhyarani, K. (2012). Specificity of systemically released rice stem volatiles on egg parasitoid, Trichogramma japonicum Ashmead behaviour. Journal of Applied Entomology, 136(10):749-760.

Regnault-Roger, C. (1997). The potential of botanical essential oils for insect pest control. Integrated Pest Management Reviews, 2(1):25-34.

Regnault-Roger, C., Vincent, C., and Arnason, J. T. (2012). Essential oils in insect control: low-risk products in a high-stakes world. Annual review of entomology, 57:405-424.

Renou, M., Nagnan, P., Berthier, A., and Durier, C. (1992). Identification of compounds from the eggs of ostrinia nubilalis and mamestra brassicae having kairomone activity on trichogramma brassicae. Entomologia Experimentalis et Applicata, 63(3):291-303. 
Ris, N., Groussier, G., Sellier, N., Marchand, A., and Warot, S. (2018). Brc "egg parasitoids collection"(epcoll). Portail Data INRAE.

Romeis, J., Shanower, T. G., and Zebitz, C. P. (1997). Volatile plant infochemicals mediate plant preference of trichogramma chilonis. Journal of Chemical Ecology, 23(11):2455-2465.

Ryan, M. and Byrne, O. (1988). Plant-insect coevolution and inhibition of acetylcholinesterase. Journal of chemical ecology, 14(10):1965-1975.

Saeidi, M., Moharramipour, S., Sefidkon, F., Aghajanzadeh, S., et al. (2011). Insecticidal and repellent activities of citrus reticulata, citrus limon and citrus aurantium essential oils on callosobruchus maculatus. Integrated Protection of Stored Products IOBC/WPRS Bulletine, 69:289-293.

Sampson, B. J., Tabanca, N., Kirimer, N., Demirci, B., Baser, K. H. C., Khan, I. A., Spiers, J. M., and Wedge, D. E. (2005). Insecticidal activity of 23 essential oils and their major compounds against adult lipaphis pseudobrassicae (davis)(aphididae: Homoptera). Pest Management Science: formerly Pesticide Science, 61(11):1122-1128.

Sanei-Dehkordi, A., Sedaghat, M. M., Vatandoost, H., and Abai, M. R. (2016). Chemical compositions of the peel essential oil of citrus aurantium and its natural larvicidal activity against the malaria vector anopheles stephensi (diptera: Culicidae) in comparison with citrus paradisi. Journal of arthropod-borne diseases, 10(4):577.

Saroukolai, A. T., Nouri-Ganbalani, G., Hadian, J., and Rafiee-Dastjerdi, H. (2014). Antifeedant activity and toxicity of some plant essential oils to colorado potato beetle, leptinotarsa decemlineata say (coleoptera: Chrysomelidae). Plant Protection Science, 50(4):207-216.

Saxena, K. and Basit, A. (1982). Inhibition of oviposition by volatiles of certain plants and chemicals in the leafhopper amrasca devastons (distant). Journal of Chemical Ecology, 8(2):329-338.

Schindelin, J., Arganda-Carreras, I., Frise, E., Kaynig, V., Longair, M., Pietzsch, T., Preibisch, S., Rueden, C., Saalfeld, S., Schmid, B., et al. (2012). Fiji: an open-source platform for biological-image analysis. Nature methods, 9(7):676-682.

Schneider, C. A., Rasband, W. S., and Eliceiri, K. W. (2012). Nih image to imagej: 25 years of image analysis. Nature methods, 9(7):671-675.

Schöller, M. and Prozell, S. (2002). Response of trichogramma evanescens to the main sex pheromone component of ephestia spp. and plodia interpunctella,(z, e)-9, 12-tetra-decadenyl acetate (zeta). Journal of Stored Products Research, 38(2):177-184.

Siviter, H. and Muth, F. (2020). Do novel insecticides pose a threat to beneficial insects? Proceedings of the Royal Society B, 287(1935):20201265.

Sousa, R. M. O., Cunha, A. C., and Fernandes-Ferreira, M. (2021). The potential of apiaceae species as sources of singular phytochemicals and plant-based pesticides. Phytochemistry, 187:112714.

Spiegelhalter, D. J., Best, N. G., Carlin, B. P., and Van Der Linde, A. (2002). Bayesian measures of model complexity and fit. Journal of the royal statistical society: Series b (statistical methodology), 64(4):583639. 
Su, Y.-S. and Yajima, M. (2015). R2jags: Using R to Run 'JAGS'. R package version 0.5-7.

Szczepanik, M., Zawitowska, B., Szumny, A., et al. (2012). Insecticidal activities of thymus vulgaris essential oil and its components (thymol and carvacrol) against larvae of lesser mealworm, alphitobius diaperinus panzer (coleoptera: Tenebrionidae). Allelopathy Journal, 30(1):129-142.

Tamo, C., Ricard, I., Held, M., Davison, A. C., and Turlings, T. C. J. (2006). A comparison of naive and conditioned responses of three generalist endoparasitoids of lepidopteran larvae to host-induced plant odours. Animal Biology, 56(2):205-220.

Toth, M., Klein, M., and Imrei, Z. (2003). Field screening for attractants of scarab (coleoptera: Scarabaeidae) pests in hungary. Acta Phytopathologica et Entomologica Hungarica, 38(3-4):323-331.

Van Lenteren, J. C. (2012). The state of commercial augmentative biological control: plenty of natural enemies, but a frustrating lack of uptake. BioControl, 57(1):1-20.

van Oudenhove, L., Mailleret, L., and Fauvergue, X. (2017). Infochemical use and dietary specialization in parasitoids: a meta-analysis. Ecology and evolution, 7(13):4804-4811.

Vet, L. E., Lenteren, J. v., Heymans, M., and Meelis, E. (1983). An airflow olfactometer for measuring olfactory responses of hymenopterous parasitoids and other small insects. Physiological Entomology, 8(1):97-106.

Vet, L. E. M. and Dicke, M. (1992). Ecology of infochemical use by natural enemies in a tritrophic context. Annual Review of Entomology, 37:141-172. A44.

Vital, R., Muchembled, J., Deweer, C., Tournant, L., Corroyer, N., and Flammier, S. (2018). Evaluation de l'intérêt de l'utilisation d'huiles essentielles dans des stratégies de protection des cultures. Innovations Agronomiques, 63:1-20.

Volkoff, A.-N., Daumal, J., Barry, P., François, M.-C., Hawlitzky, N., and Rossi, M. M. (1995). Development of Trichogramma cacoeciae marchal (hymenoptera: Trichogrammatidae): time table and evidence for a single larval instar. International Journal of Insect Morphology and Embryology, 24(4):459-466.

Vos, M. and Hemerik, L. (2003). Linking foraging behavior to lifetime reproductive success for an insect parasitoid: adaptation to host distributions. Behavioral Ecology, 14(2):236-245.

Wajnberg, E. and Colazza, S. (2013). Chemical ecology of insect parasitoids. John Wiley \& Sons.

Wang, J., Zhu, F., Zhou, X., Niu, C., and Lei, C. (2006). Repellent and fumigant activity of essential oil from artemisia vulgaris to tribolium castaneum (herbst)(coleoptera: Tenebrionidae). Journal of Stored Products Research, 42(3):339-347.

Wickham, H. (2016). ggplot2: Elegant Graphics for Data Analysis. Springer-Verlag New York.

Wilson, J. K. and Woods, H. A. (2016). Innate and learned olfactory responses in a wild population of the egg parasitoid trichogramma (hymenoptera: Trichogrammatidae). Journal of Insect Science, 16(1). 